\title{
College Students' Perceptions of Sustainability: A Regional Survey
}

\author{
Michael Myung Jeong1, Younghan Jung2, Dan Daehyun Koo ${ }^{*}$ \\ ${ }^{1}$ Department of Civil Engineering and Construction Management, Georgia Southern University, Statesboro, GA, \\ USA \\ ${ }^{2}$ Department of Engineering Technology, Old Dominion University, Norfolk, VA, USA \\ ${ }^{3}$ Department of Engineering Technology, Indiana University Purdue University Indianapolis (IUPUI), \\ Indianapolis, IN, USA \\ Email: mjeong@georgiasouthern.edu, yjung@odu.edu, "dankoo@iupui.edu
}

Received 4 November 2015; accepted 18 December 2015; published 21 December 2015

Copyright (C) 2015 by authors and Scientific Research Publishing Inc.

This work is licensed under the Creative Commons Attribution International License (CC BY).

http://creativecommons.org/licenses/by/4.0/

(c) (i) Open Access

\begin{abstract}
Understanding college students' perception of sustainability is paramount as today's students will soon be driving our economy and taking on the responsibility of maintaining a sustainable society. This study conducted a survey of college students attending two regional universities in the United States to capture their current experience levels, expectations, and perceptions with regard to various aspects of sustainability utilizing a questionnaire consisting of structured questions about sustainability knowledge/familiarity levels, green product purchase behavior, attitude-behavior relationship, and sustainability education. The results reveal useful insights into the students' views on these topics and the demographic data collected were further analyzed to identify any differences due to educational background, academic standing, and gender. The study's findings support the growing importance of encouraging sustainable behavior among college students and provide a benchmark against which to measure the effectiveness of future efforts to improve sustainability education and foster sustainable behaviors.
\end{abstract}

\section{Keywords}

Greener Product, Sustainability, Purchase Behavior, Involuntary Use, Sustainable Education

\section{Introduction}

Over the past few decades, concern over the environment has been increasing around the world. Considerable

\footnotetext{
${ }^{*}$ Corresponding author.
}

How to cite this paper: Jeong, M.M., Jung, Y. and Koo, D.D. (2015) College Students' Perceptions of Sustainability: A Regional Survey. Journal of Building Construction and Planning Research, 3, 209-220. 
effort has been made to address various environmental issues in areas such as human overpopulation, natural disasters, intensive farming production, excessive waste, water contamination, and nuclear technology. A major environmental area that is closely related to everyday human life is the use of so-called green products. A wide range of illustrative words is now being used to describe the nature of green products such as recyclable, sustainable, ecological, biodegradable, environmentally-friendly, eco-friendly, earth-friendly, planet-friendly, or going-green, but the implications of all these descriptive word are essentially alike in the sense that the green products they refer to are manufactured with some level of consideration of the need to promote healthier living for the planet and its inhabitants.

Much research has been done to explore green product and relevant consumer purchasing behavior, often referred to as "green consumerism". Follows and Jobber (2000) tested a consumer model of environmentally responsible purchase behavior and concluded that an environmentally negative product can be viewed unfavorably by consumers as threats to the environment are taken more seriously than was previously the case [1]. However, an environmentally positive product may not be purchased, despite its environmental benefit, if there is a significantly negative consequence to the consumer associated with the product; a relatively less functional green product may be passed over in favor of a conventional product that provides superior functionality. This interesting conflict between consumers' attitude toward the environment and their purchasing behavior was the focus of a study by Gupta and Ogden (2009) [2], who explored this attitude-behavior gap in green consumerism. Their results indicated that although green product purchasing behavior is greatly influenced by a consumer's attitude towards the environment, self-interest also plays a role. Their findings support those of Follows and Jobber (2000), who reported that if the cost of a green product is not within the consumer's expected price range, it is highly unlikely that they will buy it, despite his or her environmentally positive attitude. Young et al. (2010) conducted a similar study addressing this attitude-behavior inconsistency among consumers in the United Kingdom (UK) [3], showing that several important and unique factors encourage self-declared green consumers to buy more green products. All these studies on green product purchasing behavior agree that one of the underlying assumptions often made is that green consumers voluntarily make decisions on their purchases.

Although a considerable amount of the work reported in the literature has focused on voluntary consumer behavior related to the purchase of green products, few researchers have looked at people's perceptions regarding green products when those products are not purchased by the end-users but provided by others, so the consumers use the green product involuntarily. For example, it is common for colleges in the United States (US) to mandate that undergraduate students live in a dormitory in their freshmen year and even when living in a dormitory is optional some students choose to live in one for their own reasons. College dormitory buildings are usually furnished with a standard range of fixtures, some of which may be energy saving products, particularly items such as low energy light bulbs, low volume showerheads and toilet flushes. While the voluntary purchase and consumption of green products are likely to be directly associated with an end-user's perceptions regarding the environment (for example sustainable behavior or social responsibility as a so-called "Earth Citizen"), the involuntary use of green products may produce different perceptions and insights from the end-user's standpoint.

Given this background, the primary objective of the study reported in this paper was to capture college students' perceptions of green products, purchasing behavior, and sustainability in general. To accomplish this objective, the study utilized a structured questionnaire to conduct a survey of male and female students attending two regional colleges in the United States and living in college dormitories. The water-saving showerheads installed in the colleges' dormitory buildings were employed as the green product that the students living in the selected buildings involuntarily used. The water-saving showerheads are the only option within the selected buildings and no conventional showerheads are provided in those particular buildings. The water flow rate, water volume, and water pressure of the water-saving showerheads are relatively less than those of a regular showerhead for water-saving purposes, and consequently the resulting level of serviceability or functionality may be considered inferior to conventional showerheads by some students. The following section provides background information on showerheads in general to demonstrate their function as a plumbing fixture in a building.

\section{Showerheads}

Building design elements associated with fixture choice can have a considerable impact on both water and energy consumption over the service life of a building [4]. Each plumbing fixture installed in a building's water supply system has a specified flow rate that must be achieved in order for the fixture to properly perform its de- 
signed function. Flow rate is a direct measure of the volume of water coming out of the fixture and is typically measured in gallons per minute or gpm in the US and a maximum and minimum allowed flow rate is specified for each plumbing fixture. The maximum allowed flow rate prevents the excess use of water and, in the case of showerheads, the maximum flow rate is limited to $2.5 \mathrm{gpm}$ by the US federal government's Energy Policy Act of 1992 [5]. The minimum flow rate ensures an adequate amount of water reaches the showerhead, as an inadequate flow rate and water pressure lessens the originally intended functionality of the showerhead and, accordingly, its serviceability for the user. In 2010, the US Environmental Protection Agency (EPA) published new water conservation guidelines for showerheads as part of its "Water Sense Program" [6]. These guidelines require showerhead manufacturers to provide information about the maximum permitted flow rates for their products and to test them in accordance with the procedures specified in ASME A112.18.1/CSA B125.1 [7]. This specified value recommended by the EPA should be equal to or less than $2.0 \mathrm{gpm}$, which is slightly stricter than the $2.5 \mathrm{gpm}$ allowed by the earlier federal regulations.

According to news reports (Kinver, 2011) taking a shower requires 62 liters (16.4 gallons) of water on average in the UK, while taking a bath needs 80 liters (21.1 gallons) on average, suggesting that although there is a difference in the water consumption between showers and baths, the two are broadly comparable. The reporter noted that taking showers, which last eight minutes on average, would typically cost a family of four in the UK $£ 416$ a year [8]; using a "power" shower to add extra water pressure to increase user satisfaction would require twice as much water and energy and thus double the cost. A low flow rate showerhead can thus have a significant impact on water and energy consumption, and hence using a water-saving green product would satisfy the criteria "being green".

\section{Survey Design}

\subsection{Sample Collection}

Sample data was collected via a questionnaire handed out during randomly selected classes at two regional universities in the US. A total of 242 students participated in Sections 1 and 2 of the survey. Forty seven students were identified as having had experience using a water-saving showerhead in one of the college dormitories and Section 3 of their completed questionnaires were used for this investigation of the college students' perceptions of the involuntary use of a green product.

\subsection{Questionnaire Design and Sample Measures}

The questionnaire consisted of three sections. The first section collected general demographic data about the respondents such as their current year at the university, gender, major, academic standing, and age group. This data was employed to explore the perceptions of green products and sustainability among the students by specific groups: gender, academic standing or Grade Point Average (GPA), and educational background or major. The second section was divided into three subgroups: 1) general perception of sustainability, 2) sustainability education, and 3) green product purchase behavior. Most of the responses in this section were based on a fivepoint Likert scale (either $1=$ strongly disagree to $5=$ strongly agree; or $1=$ not confident to $5=$ strongly confident, depending on the type of question), with two yes-or-no questions (Questions \#1 and \#4). The third section of the questionnaire focused specifically on capturing perceptions of the use of the water-saving showerhead from those students who had experienced using it involuntarily in the dormitory, utilizing a yes-or-no response for question 1 and a five-point Likert scale for Question 3. Table 1 presents the questionnaire content.

\section{Results and Interpretation}

\section{Part I: Demographic Information}

The demographic information gathered by the survey is presented in Table 2. Although the research team attempted to randomly collect the sample data, the gender sample distribution was found to be noticeably skewed toward male respondents, with the male sample group accounting for about two third of the data. This was attributed to the fact that more than half of the samples were collected in Engineering classes, where students are predominantly male in the surveyed universities. Under the "Major" category in the table, the research team were particularly interested in exploring any differences in sustainability perceptions between the Construction Management and Civil Engineering (CECM) students, and those enrolled in other majors in order to test the 
Table 1. Survey questionnaires.

\section{Part I: Demographic Questions}

1. Year in the university (Freshman, Sophomore, Junior, Senior) ${ }^{a}$

2. Gender (Male, Female) ${ }^{\mathrm{a}}$

3. Major

4. Grade Point Average $\mathrm{e}^{\mathrm{a}}$

\section{Part II: Questions related to Sustainability and Green Products}

1. Have you ever heard of the concept of sustainability?

2. Are you familiar with sustainability? ${ }^{\mathrm{c}}$

3. What is your level of knowledge regarding sustainability? ${ }^{c}$

4. Have you ever taken any courses related to sustainability? ${ }^{\mathrm{b}}$

5. Do you think the classes on sustainability affect your attitude toward the environment and sustainability?

6. Do you believe that higher education must teach sustainability for a complete undergraduate curriculum. ${ }^{c}$

7. Do you consider sustainability when you purchase products. ${ }^{c}$

8. Do you think you should pay extra money for sustainable building products? ${ }^{\mathrm{c}}$

9. Do you have any experience installing or using any green products such as energy-saving light bulbs? ${ }^{c}$

10. Do you believe that it is very important to use green products instead of conventional products?

11. How concerned are you about saving water in your daily activities? ${ }^{c}$

\section{Part III: Experience of Water-Saving Showerheads}

1. Did you realize that water saving showerheads have been installed in the dorm showers? ${ }^{\mathrm{b}}$

2. How long do you take in the shower? ${ }^{\mathrm{a}}$

3. Are you satisfied with your water saving showerhead compared to a conventional showerhead?c

4. If you are not satisfied with the water-saving showerhead, what is your greatest concern? ${ }^{\mathrm{a}}$

5. What is your favorite feature of the water-saving showerhead? ${ }^{a}$

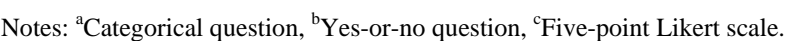

Table 2. Summary of demographic information: Questionnaire Part I.

\section{Gender}

Male

Female

Total

\section{Current Year}

Freshman

Sophomore

Junior

Senior

Graduate

Total
N

Proportion (\%)

100.0 


\section{Continued}

\begin{tabular}{ccc}
\hline Major & & \\
Construction Management \& Civil Engineering & 71 & 29.3 \\
Other departments & 171 & 70.7 \\
Total & 242 & 100.0 \\
GPA & & 0.8 \\
$<2.0$ & 2 & 10.3 \\
$2.0-2.49$ & 25 & 31.4 \\
$2.5-2.99$ & 76 & 36.8 \\
$3.0-3.49$ & 89 & 19.8 \\
$3.5-4.0$ & 48 & 0.8 \\
No answer & 2 & 100.0 \\
\hline
\end{tabular}

hypothesis that the CECM students would be more knowledgeable and concerned regarding green building approaches and fixtures. In terms of the current academic year of the survey respondents, freshman and graduate students were less well represented in the survey respondents (4.2\%) than the sophomore, junior, and senior students (95.8\%). The academic standing or GPA data showed a normal distribution among the samples.

Part II: Perceptions Regarding Sustainability

Table 3 and Figure 1(a) and Figure 1(b) show the responses to Part II of the survey, which was designed to elicit students' perceptions of sustainability in three areas: sustainability knowledge, sustainability education, and green product purchase behavior. The number of responses shown in the table varies slightly because blank responses were not included in the data analysis.

In the first section, which deals with the respondent's level of familiarity with/knowledge of sustainability, $86.4 \%$ of the students responded that they had heard of the concept of sustainability (Question \#1) and about $35 \%$ of the students considered themselves familiar with the topic, selecting 4 or 5 on the Likert scale in their responses to Question \#2. However, the average score for this question (3.02/5.0) indicates the familiarity level to be mediocre. Interestingly, they seemed to be less confident regarding their knowledge of sustainability, with only 18.2\% of the students selecting 4 and 5as their response to Question \#3 which asked about their sustainability knowledge level. The low average score for this question (2.52/5.0) also supports this finding. This result could be interpreted as showing that although many students are exposed to green concepts via the media, internet, books and magazines, and conversations, and thus believe they are quite familiar with the general concept, they are only rarely exposed to the type of formal presentations on sustainability issues that would intensively educate them about sustainability, leaving them less confident about their knowledge of the topic.

This conjecture is supported by the results for the second section of Part II, which investigates students' thoughts on sustainability education. For Question \#4, over two thirds of the respondents (70.5\%) said that they had not taken any sustainability-related courses at the time of the survey, which is aligned with the response to Question \#3 in the previous section. Interestingly, $46.1 \%$ of the respondents selected 4 and 5 on Question \#5, indicating that they expected that sustainability education would influence their attitude toward the environment, whereas only $16.9 \%$ of the students selected 1 and 2 for this question, expressing their opinion that education would not. The average score for this question of 3.41 leans toward a positive opinion regarding the utility of sustainability education. For Question \#6, which asked whether they thought there was a need for a sustainability course to be included in the undergraduate curriculum, $42.7 \%$ of the students chose 4 and 5 , and the average score for this question was 3.32. This result supports the generally positive perception revealed in Question \#5, with around the same portion of the students (42.7\%) again selecting a mediocre score (3) and only $14.5 \%$ choosing 1 and 2 . This result may suggest that rather than developing and incorporating a regular sustainability course in the curriculum, a specialized certification program could be a viable alternative for undergraduate students. 
Q2: Familiarity w/ Sustainability
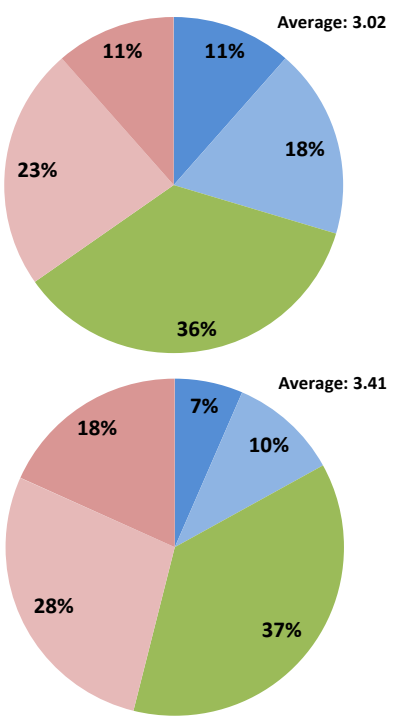

Scale $1 \square$ Scale 2

(a)

Q7: Sustainability Consideration

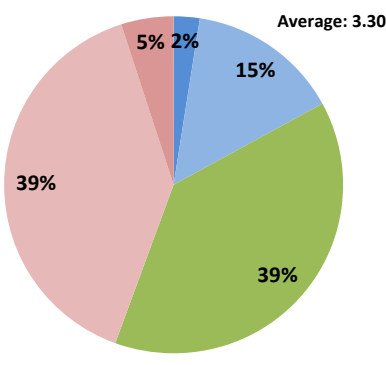

Q9: Experience w/ Green Product

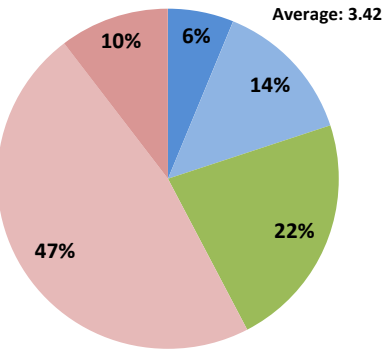

Q11: Concern over Saving Water

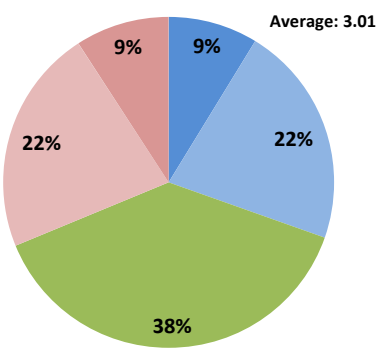

(b)
Q3: Knowledge in Sustainability
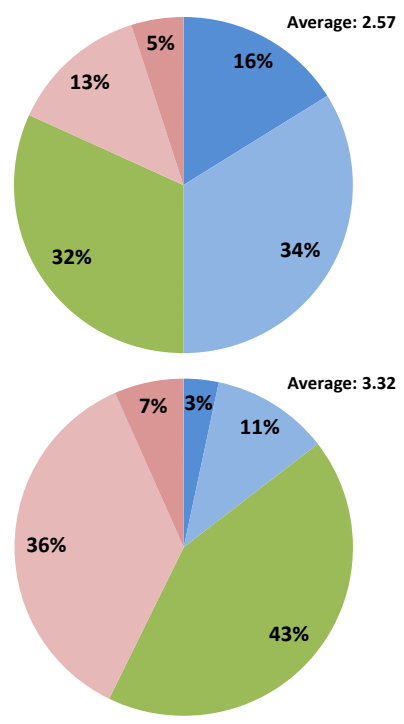

Scale 4 Scale 5

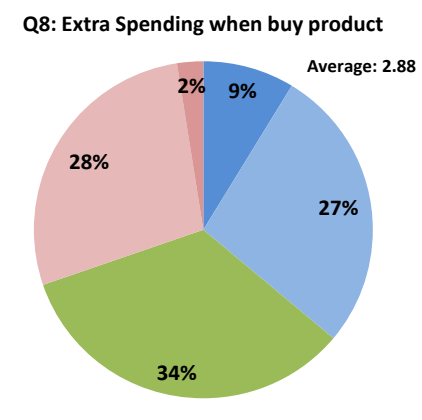

Q10: Importance of Green Product

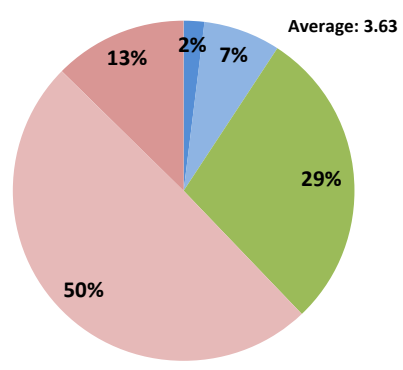

Scale 1

Scale 2

Scale 3

Scale 4

Scale 5

Figure 1. (a) Questionnaire Part II: Pie Charts for Questions 2, 3, 5, and 6; (b) Questionnaire Part II: Pie Chart for Questions 7 to 11. 
Table 3. Summary of the survey results: Questionnaire Part II.

\begin{tabular}{|c|c|c|c|c|c|c|c|c|}
\hline Part II & $\mathbf{N}$ & 1 & 2 & 3 & 4 & 5 & Avg. & Std. \\
\hline \multicolumn{9}{|l|}{ Section 1. Awareness and Knowledge } \\
\hline 1. Awareness of the concept of sustainability & 242 & \multicolumn{7}{|c|}{ Yes: 209 (86.4\%), No: 33 (13.6\%) } \\
\hline 2. Level of familiarity with sustainability & 236 & $\begin{array}{c}27 \\
11.4 \%\end{array}$ & $\begin{array}{c}43 \\
18.2 \%\end{array}$ & $\begin{array}{c}84 \\
35.6 \%\end{array}$ & $\begin{array}{c}55 \\
23.3 \%\end{array}$ & $\begin{array}{c}27 \\
11.4 \%\end{array}$ & 3.02 & 1.15 \\
\hline 3. Level of knowledge regarding sustainability & 242 & $\begin{array}{c}39 \\
16.1 \%\end{array}$ & $\begin{array}{c}82 \\
33.9 \%\end{array}$ & $\begin{array}{c}77 \\
31.8 \%\end{array}$ & $\begin{array}{c}32 \\
13.2 \%\end{array}$ & $\begin{array}{c}12 \\
5.0 \%\end{array}$ & 2.57 & 1.06 \\
\hline \multicolumn{9}{|l|}{ Section 2. Sustainability Education } \\
\hline 4. Any sustainability course taken & 241 & \multicolumn{7}{|c|}{ Yes: 71 (29.5\%), No: 170 (70.5\%) } \\
\hline 5. Influence of sustainability course & 230 & $\begin{array}{c}15 \\
6.5 \%\end{array}$ & $\begin{array}{c}24 \\
10.4 \%\end{array}$ & $\begin{array}{c}85 \\
37.0 \%\end{array}$ & $\begin{array}{c}64 \\
27.8 \%\end{array}$ & $\begin{array}{c}42 \\
18.3 \%\end{array}$ & 3.41 & 1.10 \\
\hline 6. Need for a sustainability course in the curriculum & 241 & $\begin{array}{c}8 \\
3.3 \%\end{array}$ & $\begin{array}{c}27 \\
11.2 \%\end{array}$ & $\begin{array}{c}103 \\
42.7 \%\end{array}$ & $\begin{array}{c}87 \\
36.1 \%\end{array}$ & $\begin{array}{c}16 \\
6.6 \%\end{array}$ & 3.32 & 0.88 \\
\hline \multicolumn{9}{|l|}{ Section 3. Purchase Behavior } \\
\hline 7. Sustainability consideration & 241 & $\begin{array}{c}6 \\
2.5 \%\end{array}$ & $\begin{array}{c}35 \\
14.5 \%\end{array}$ & $\begin{array}{c}93 \\
38.6 \%\end{array}$ & $\begin{array}{c}95 \\
39.4 \%\end{array}$ & $\begin{array}{c}12 \\
5.0 \%\end{array}$ & 3.30 & 0.87 \\
\hline 8. Extra spending on green products & 241 & $\begin{array}{c}21 \\
8.7 \%\end{array}$ & $\begin{array}{c}66 \\
27.4 \%\end{array}$ & $\begin{array}{c}81 \\
33.6 \%\end{array}$ & $\begin{array}{c}67 \\
27.8 \%\end{array}$ & $\begin{array}{c}6 \\
5.0 \%\end{array}$ & 2.88 & 0.99 \\
\hline 9. Experience with green products & 241 & $\begin{array}{c}15 \\
6.2 \%\end{array}$ & $\begin{array}{c}33 \\
13.7 \%\end{array}$ & $\begin{array}{c}54 \\
22.4 \%\end{array}$ & $\begin{array}{c}114 \\
47.3 \%\end{array}$ & $\begin{array}{c}25 \\
10.4 \%\end{array}$ & 3.42 & 1.05 \\
\hline 10. Level of importance of green products & 240 & $\begin{array}{c}4 \\
1.7 \%\end{array}$ & $\begin{array}{c}15 \\
6.3 \%\end{array}$ & $\begin{array}{c}59 \\
24.7 \%\end{array}$ & $\begin{array}{c}102 \\
42.7 \%\end{array}$ & $\begin{array}{c}26 \\
10.9 \%\end{array}$ & 3.63 & 0.84 \\
\hline 11. Level of concern for saving water & 239 & $\begin{array}{c}21 \\
8.8 \%\end{array}$ & $\begin{array}{c}52 \\
21.7 \%\end{array}$ & $\begin{array}{c}92 \\
38.3 \%\end{array}$ & $\begin{array}{c}53 \\
22.1 \%\end{array}$ & $\begin{array}{c}22 \\
9.2 \%\end{array}$ & 3.01 & 1.08 \\
\hline
\end{tabular}

The third section under Part II consisted of five questions exploring the green product purchase behavior of students. For Question \#7, the average score of 3.30 shows that the students do tend to consider sustainability when they purchase products. However, the responses to Question \#8 suggest that they would be unlikely to spend extra money to purchase green products based on the average score of 2.88 for this question. This attitude-behavior dilemma reflects the findings from previous studies [1]-[3] described earlier. For Question \#9, more than half of the respondents (57.7\%) reported some experience with using energy-saving products. Consistent with this response, the result for Question \#10 was also positive with regard to the level of importance they assigned to green products. The averages for Questions \#9 and \#10 were 3.42 and 3.63 respectively, indicating the respondents' generally positive attitude towards green products. Question \#11 asked about the students' perceptions concerning the need to save water. The results here again reinforced the attitude-behavior gap issue; the somewhat mediocre average score of 3.01 for this question suggests that when the students used water in the course of their daily activities (e.g., for showering, washing, and so on), they experienced some conflict between the competing priorities of using enough water for self-satisfaction and saving water for sustainability.

Part III: Involuntary Use of a Green Product

The third section of the survey explored college students' perceptions of the involuntary use of a green product. Among the 242 students who responded to the survey, 47 were identified as residing in a dormitory and thus having experienced using the water-saving showerheads. The results for Part III are presented in Table 4. In Question \#1, the students were asked whether they were aware of the green characteristics of the showerhead. One third of the students had not even realized that the showerhead in the dormitory was an energy-saving green product. In Question \#2 which asked about the average shower time, about half of the students thought that they took 10 to 20 minutes, while $38.3 \%$ and $10.6 \%$ of the students responded that they took 5 to 10 minutes and less than 5 minutes, respectively. Only one person claimed to take a shower that was longer than 20 minutes. Questions \#3 and \#4 dealt with the most important aspect of this part of the survey. An average score of 3.1 was reported for Question \#3, indicating that the students' level of satisfaction with the water-saving showerhead leaned very slightly towards favorable, with about a quarter of the students (25.5\%) selecting 4 and 5, and a simi- 
Table 4. Summary of the survey results: Questionnaire Part III.

\section{Part III Question No.}

1. Awareness of the showerhead

Yes
No
Total

\section{Amount of shower time}

$<5$ min.
5 - 10 min.
10 - 20 min.
$>20$ min.
No answer
Total

3. Satisfaction with the showerhead ${ }^{*}$

Very dissatisfied
Dissatisfied
Neutral
Satisfied

Very satisfied

No answer

Total

Likert Scale Average: 3.10
4. If not satisfied, the reason
$\mathbf{N}$

Water pressure
Appearance
Control
Cleaning
Other

46.8

4.3

8.5

17.0

10.6

12.8

100.0

5. Favorite feature

Massage function
Appearance
Cleaning
Other
None

No answer

Total 
lar portion (23.4\%) selecting 1 and 2. When asked for reasons for their dissatisfaction, 22 of the 47 students (46.8\%) singled out the water pressure, indicating that it is the water-saving showerhead's lower water pressure that diminishes the users' satisfaction and the perceived serviceability level of taking a shower with the green showerhead product. A number of other minor reasons were also mentioned by the students, including the showerhead's appearance, controls, and cleanliness. In the final question, Question \#5, when students were asked to name a favorite feature of the showerhead, 31.9\% said they had no favorite feature, reflecting the earlier complaints about the showerhead.

\section{Sustainability Perception by Gender, Major, and Academic Standing}

The survey results and interpretation presented in the previous section were primarily based on whether the responses for each question indicated negative (scale points 1 and 2), neutral (scale point 3) or positive (scale points 4 and 5) opinions. This section explores these scores in the context of survey participants' characteristics, specifically their gender, educational background, and academic standing using statistical means. A Chi-Square test of association was used to evaluate two hypothesized statements consisting of a pair of null $\left(\mathrm{H}_{0}\right)$ and alternative $\left(\mathrm{H}_{1}\right)$ hypotheses for each characteristic. For example, the following statements focus on the association, if any, between survey participants' gender and their responses to each question.

$\mathrm{H}_{0}$ : There is no statistical evidence of an association between gender and the responses to a selected question.

$\mathrm{H}_{1}$ : There is statistical evidence of association between gender and the responses to a selected question.

To accept or reject these paired hypotheses, a Pearson's p-value was calculated. If the p-value was greater than 0.05 (i.e., $95 \%$ confidence level), $\mathrm{H}_{0}$ was accepted (and $\mathrm{H}_{1}$ automatically rejected), indicating there to be no statistical evidence to associate the characteristics with the survey results. If the p-value was less than 0.05 , then $\mathrm{H}_{1}$ was rejected (and $\mathrm{H}_{0}$ automatically accepted), indicating that there was indeed evidence of an association between the two. Table 5 summarizes the Chi-Square test results, including the p-values obtained from the statistical analyses and the consequent decision reached regarding the association, if any, between each characteristic and the opinion expressed for each question. Only those questions in Part II that were surveyed with five-point Likert scales were evaluated for this statistical test. The MINITAB $^{\circledR}$ (ver. 17) statistics package was utilized for this analysis. In interpreting the results of the Chi-Square test, it should be noted that the test does not determine if a specific gender, major, or level of academic standing has a stronger or weaker association than its counterparts. Rather, the Chi-Square result simply determines whether or not there is an association. However, examining the proportion of answers for each characteristic does suggest which groups of respondents tended to express stronger opinions.

\subsection{Effect of Gender on Attitudes towards Sustainability}

Zelezny et al. (2000) studied gender differences in general environmental attitudes and behaviors across 14 countries and concluded that there was strong evidence to indicate that environmentalism did indeed depend upon gender, with females expressing stronger attitudes and behaviors than man [9]. Our results provide additional evidence to support Zelezny's conclusions in several areas, especially the responses to Questions \#2 and \#3 in Section 1. The p-values for these questions are both below the threshold value of 0.05 , as shown in Table 5. For Question \#2, the analysis of the data indicates that $70 \%$ of the female students selected positive responses (scores of 4 and 5), while only 46\% of the male students did so; similarly for Question \#3, 21\% of the male students selected positive responses, while $42 \%$ of female students did so.

With regard to the topics in Sections 2 and 3 (sustainability education and green product purchase behavior), our results revealed no statistical evidence to suggest that positive or negative opinions on the questions differ by student gender, with the sole exception being for Question \#7: Do you consider sustainability when you purchase products. For this particular question, the analysis indicates that male students tend to consider sustainability more when they purchase products. Except for Question \#7, our results contradicted those reported by many previous studies [9]-[12] where the authors did observe gender differences in similar topics such as environmental attitude, responsibility, peer influence, and purchasing green products. However, there have been a few other studies that found no difference due to gender [13] [14]. Looking at the complex picture revealed by these often contradictory findings reported regarding the impact of gender on attitudes towards the environment, it appears likely that the results depend largely on the characteristics of the sample population used for each study. 
Table 5. P-values from the Chi-Square test and the association decision.

\begin{tabular}{|c|c|c|c|c|c|c|}
\hline \multirow{2}{*}{ Part II Questions } & \multicolumn{2}{|c|}{ Gender } & \multicolumn{2}{|c|}{ Major } & \multicolumn{2}{|c|}{ GPA } \\
\hline & P-value & Associated? & P-value & Associated? & P-value & Associated? \\
\hline \multicolumn{7}{|c|}{ Section 1. Awareness and Knowledge } \\
\hline 2. Familiarity with sustainability & 0.005 & Yes & 0.988 & No & 0.007 & Yes \\
\hline 3. Knowledge of sustainability & 0.006 & Yes & 0.020 & Yes & 0.091 & No \\
\hline \multicolumn{7}{|c|}{ Section 2. Sustainability Education } \\
\hline 5. Influence of sustainability course & 0.174 & No & 0.064 & No & 0.152 & No \\
\hline 6. Sustainability course in curriculum & 0.403 & No & 0.007 & Yes & 0.859 & No \\
\hline \multicolumn{7}{|c|}{ Section 3. Purchase Behavior } \\
\hline 7. Sustainability consideration & 0.042 & Yes & 0.831 & No & 0.000 & Yes \\
\hline 8. Extra spending on green products & 0.428 & No & 0.080 & No & 0.026 & Yes \\
\hline 9. Experience with green products & 0.769 & No & 0.891 & No & 0.480 & No \\
\hline 10. Importance of green products & 0.441 & No & 0.308 & No & 0.371 & No \\
\hline 11. Concern with saving water & 0.052 & No & 0.479 & No & 0.300 & No \\
\hline
\end{tabular}

\subsection{Effect of Educational Background on Attitudes towards Sustainability}

A similar analysis was carried out for respondents educational background. As noted earlier, the sample group was divided into two subgroups, with those students who were majoring in CECM assigned to one subgroup and the remaining students to the other. The results revealed that for all questions except for Questions \#3 and \#6 in Section 2, there was no apparent difference between the CECM students and those in other majors. The responses to Question \#3 were more interesting, however. Here, only 14\% of the CECM students claimed to be confident or very confident about their knowledge of sustainability, while $28 \%$ of the students in other majors expressed confidence in their level of sustainability knowledge. For Question \#6, 89\% of the CECM students considered that a sustainability course should be incorporated into the undergraduate curriculum, while a smaller majority (68\%) of the students in other majors thought so.

\subsection{Effect of Academic Standing on Attitudes towards Sustainability}

In this category, GPA was utilized as a proxy for academic standing: students with GPAs below 3.0 were assigned to one subgroup and those with a GPA equal to or above 3.0 were assigned to the other subgroup. Students' responses on three out of the nine questions in Part II were found to have an association with the students' academic standing. For Question \#2, the students with higher GPAs showed more familiarity (63\%) with sustainability than the academically lower performing group (41\%); for Question \#7, the better performing group (75\%) appeared to consider sustainability more when purchasing products than the others (43\%); and for Question \#8, 53\% of the students with higher GPAs expressed a greater willingness to spend extra money on buying green products while only $35 \%$ of those with lower GPAs expressed the same opinion.

\section{Limitations and Suggestions for Future Research}

The results presented in this study were obtained from student samples recruited from only two regional universities located in the southeastern United States with a relatively limited number of participants. Hence, the findings should be treated with some cautioned and not be generalized until further studies with more data from additional sources around the US are conducted. As both the universities participating in the study recruit their students largely from the local area, a regional bias could also be affecting the findings as various cultural factors in the region may influence the survey participants' responses regarding their perceptions of sustainability. This regional factor may therefore be an important variable in identifying the sustainability perspective of college students; although this was not analyzed in the current study, it may be a fruitful area for future research. Also, the study would have produced more reliable findings, especially in understanding the perceptions of col- 
lege students about the involuntary use of green products, if the sample size were expanded to include a larger population and a greater range of green products. The questionnaire design under Part III could be developed further and made more specific to conduct a more elaborate exploration of these issues and a future study could usefully address these limitations. Moreover, future research could be conducted over a longer period of time as a longitudinal study to track how students' perceptions change over time.

\section{Summary of Findings}

On the basis of this study, the findings can be summarized as follows:

1. Although many college students think they know about and are familiar with the concept of sustainability, they are not fully confident in their level of knowledge in this area. This result may be attributed to a lack of formal education on sustainability.

2. Many college students believe that sustainability education has the potential to influence their behavior and attitude towards the environment. Regarding the inclusion of a sustainability course in the undergraduate curriculum, opinions are divided. This result may suggest that instead of incorporating a regular sustainability course in the core curriculum, a seminar or short-term certificate program may be a viable option.

3. Many college students do consider the environment when they purchase products. However, the attitudebehavior dilemma is triggered when they have to spend extra money on the purchase.

4. Many college students have experience using energy saving products and they understand the importance of doing so. However, when they use water in their daily activities, many of the students are less concerned about saving water. This result is aligned with the aforementioned attitude-behavior dilemma.

5. Regarding their level of satisfaction with the dormitory water-saving showerheads, the student opinion is again split. Those who do not favor the shower head function specifically criticize the low water pressure of the showerhead, which is directly related to the green product functionality issue.

6. There is a gender difference in the students' familiarity and knowledge of sustainability, with female students appearing to be more familiar and knowledgeable.

7. This gender difference also appears when the students purchase products, but in contrast to Finding 6, male students tend to consider the environment more when buying products.

8. Educational background (in this case, CECM and other majors) is not a strong factor for sustainability issues except for two areas: knowledge level and the inclusion of a sustainability course in the undergraduate curriculum. CECM students seem to be relatively less confident about their sustainability knowledge than students in other majors. Regarding the advisability of incorporating a sustainability course in the curriculum, CECM students were more likely to consider it a good idea to do so than those in other majors.

9. The students with a better academic standing expressed a greater familiarity with sustainability concepts and also tended to consider sustainability more when purchasing products. Furthermore, they were more willing to spending a little extra to buy green products. No evidence was found to suggest that academic standing was associated with any of the other sustainability topics covered in the survey.

\section{Conclusion}

Understanding college students' perceptions of sustainability is important because they will shortly become the generation who is responsible for driving the economy and maintaining a sustainable society. The findings of this study support the growing awareness of the importance of sustainable behavior among today's student body, encourage socially responsible behavior, provide a benchmark against which to measure the impact of future changes to sustainability education and foster sustainable behaviors over time among the public. The study's findings revealed interesting insights related to a number of sustainability topics and demonstrated how challenging it is to draw concrete conclusions on the subject based on a limited amount of regionally constrained sample data. However, in spite of this we believe that the survey results provide evidence that supports many of the findings of previous studies in this area as well as useful information to help guide future studies on similar subjects.

\section{References}

[1] Follows, S.B. and Jobber, D. (2000) Environmentally Responsible Purchase Behavior: A Test of a Consumer Model. European Journal of Marketing, 34, 723-746. http://dx.doi.org/10.1108/03090560010322009 
[2] Gupta, S. and Ogden, D.T. (2009) To Buy or Not to Buy? A Social Dilemma Perspective on Green Buying. Journal of Consumer Marketing, 26, 376-391. http://dx.doi.org/10.1108/07363760910988201

[3] Young, W., Hwang, K., McDonald, S. and Oates, C.J. (2010) Sustainable Consumption: Green Consumer Behaviour When Purchasing Products. Sustainable Development, 18, 20-31.

[4] Gosse, J.F. (2006) Mechanical and Electrical Systems for Construction Managers. American Technical Publishers Inc., Orland Park.

[5] US Department of Energy (1992) Energy Policy Act of 1992. http://www.afdc.energy.gov/pdfs/2527.pdf

[6] US Environmental Protection Agency (2010) EPA WaterSense (WaterSense Specification for Showerheads). http://www.epa.gov/WaterSense/docs/showerheads_finalspec508.pdf

[7] The American Society of Mechanical Engineers (2012) Plumbing Supply Fittings. https://www.asme.org/products/codes-standards/a112181csa-b1251-2012-plumbing-supply-fittings

[8] Kinver, M. (2011) People’s Showering Habits Revealed in Survey. BBC News, BBC News Service, London.

[9] Zelezny, L.C., Chua, P.-P. and Aldrich, C. (2000) Elaborating on Gender Differences in Environmentalism. Journal of Social Issues, 56, 443-457. http://dx.doi.org/10.1111/0022-4537.00177

[10] Lee, K. (2009) Gender Differences in Hong Kong Adolescent Consumers' Green Purchasing Behavior. Journal of Consumer Marketing, 26, 87-96. http://dx.doi.org/10.1108/07363760910940456

[11] Mostafa, M.M. (2007) Gender Differences in Egyptian Consumers’ Green Purchase Behaviour: The Effects of Environmental Knowledge, Concern and Attitude. International Journal of Consumer Studies, 31, 220-229. http://dx.doi.org/10.1111/j.1470-6431.2006.00523.x

[12] Tikka, P.M., Kuitunen, M.T. and Tynys, S.M. (2000) Effects of Educational Background on Students’ Attitudes, Activity Levels, and Knowledge Concerning the Environment. The Journal of Environmental Education, 31, 12-19. http://dx.doi.org/10.1080/00958960009598640

[13] Arcury, T.A. and Christianson, E.H. (1993) Rural and Urban Differences in Environmental Knowledge and Actions. The Journal of Environmental Education, 25, 19-25. http://dx.doi.org/10.1080/00958964.1993.9941940

[14] Wiidegren, Ö. (1998) The New Environmental Paradigm and Personal Norms. Environment and Behavior, 30, 75-100. http://dx.doi.org/10.1177/0013916598301004 